\title{
Leaf-Miners Co-opt Microorganisms to Enhance their Nutritional Environment
}

\author{
Mélanie Body • Wilfried Kaiser • Géraldine Dubreuil • \\ Jérôme Casas • David Giron
}

Received: 30 April 2013 / Revised: 29 May 2013 / Accepted: 4 June 2013 /Published online: 27 June 2013

(C) Springer Science+Business Media New York 2013

\begin{abstract}
Organisms make the best of their mother's oviposition choices and utilize specific feeding options that meet energetic requirements and cope with environmental constraints. This is particularly true for leaf-miner insects that develop enclosed in the two epidermis layers of a single leaf for their entire larval life. Cytokinins (CKs) play a central role in plant physiology - including regulation of senescence and nutrient translocation - and, as such, can be the specific target of plant exploiters that manipulate plant primary metabolism. 'Green-islands' are striking examples of a CKinduced phenotype where green areas are induced by plant pathogens/insects in otherwise yellow senescent leaves. Here, we document how the leaf-miner caterpillar Phyllonorycter blancardella, working through an endosymbiotic bacteria, modifies phytohormonal profiles, not only on senescing (photosynthetically inactive) but also on normal (photosynthetically active) leaf tissues of its host plant (Malus domestica). This leaf physiological manipulation allows the insect to maintain sugar-rich green tissues and to create an enhanced nutritional microenvironment in an otherwise degenerating context. It also allows them to maintain a nutritional homeostasis even under distinct leaf environments. Our study also highlights that only larvae harboring bacterial symbionts contain significant amounts of CKs that are most likely not plant-derived. This suggests that insects are able to provide CKs to the plant through their symbiotic association, thus extending further the role of insect bacterial symbionts in plant-insect interactions.
\end{abstract}

Keywords Leaf-miner $\cdot$ Cytokinins $\cdot$ Endophytic plant parasite $\cdot$ Endosymbiont $\cdot$ Hormonal manipulation

M. Body $•$ W. Kaiser · G. Dubreuil · J. Casas $\cdot$ D. Giron $(\triangle)$ Institut de Recherche sur la Biologie de l'Insecte, UMR 7261 CNRS/Université François-Rabelais, UFR Sciences et Techniques, 37200 Tours, France

e-mail: david.giron@univ-tours.fr

\section{Introduction}

Cytokinins (CKs) are plant hormones that play a key role in plant morphology, plant defense, leaf senescence, and source-sink relationships (Erb et al. 2012; Meldau et al. 2012; Mok and Mok 2001; Sakakibara 2006). They are key regulators in plant-insect-microbe interactions and play a central role in plant colonization and exploitation by various plant-associated organisms, including both antagonists and mutualists (Giron et al. 2013). These phytohormones may have been the targets of arthropods and pathogens over the course of the "evolutionary arms race" between plants and their biotic partners to "hijack" plant metabolism and development enabling them to successfully invade the plant. For instance, accumulation of CKs in infected leaves is a common feature observed in numerous plant-biotic interactions (Walters and McRoberts 2006; Walters et al. 2008). There has been considerable debate about the likely origin of CKs in infected leaves, as it is not yet clear whether they are produced by the pathogen/insect or by the plant. Indeed, pathogens and herbivorous insects potentially influence the levels of phytohormones by inducing plant genes involved in CK biosynthesis, degradation, or response, but they also can produce and secrete relevant phytohormones themselves (Farnsworth 2004; Giron et al. 2013; Jameson 2000; Robert-Seilaniantz et al. 2007; Walters et al. 2008). In the case of arthropods, CK-induced phenotypes can be mediated by their bacterial symbionts, giving rise to intricate plantmicrobe-insect interactions (Kaiser et al. 2010).

A clear example of a CK-induced phenotype is the formation, after pathogen or insect attack, of spectacular green and metabolically active areas in otherwise yellow senescent leaves known as 'green-islands' (Engelbrecht et al. 1969; Giron et al. 2007; Kaiser et al. 2010; Walters and McRoberts 2006; Walters et al. 2008). In these islands, nutrients mainly sugars - are redirected towards the infection site where host cell death is delayed. As CKs strongly impact 
plant sugar metabolism, biotic invaders can specifically affect CKs, thus redirecting plant resources for their own benefit (Giron et al. 2013; Lara et al. 2004). Indeed, these phytohormones have been found to induce expression of extracellular invertases and hexose transporters that result in the transport and accumulation of nutrients at infection sites (Ehneß and Roitsch 1997; Godt and Roitsch 1997; Mothes 1964; Lara et al. 2004). Pathogens and herbivorous insects also manipulate plant primary metabolism to their own benefit. Nutrients are redirected to the infection site, which, thus, behaves as a metabolic sink that fuels pathogens or insect energetic requirements for growth, survival, and reproduction. This has been demonstrated clearly, for example, with radioactively labeled plant nutrients that are preferentially transported and accumulated in specific areas exploited by pathogens and herbivorous insects (Gottlieb and Garner 1946; Mothes and Engelbrecht 1961; Shaw and Samborski 1956). The life-cycles of many organisms are constrained by the seasonality of resources. Strategies adopted by a biotic invader that increase the "longevity" of leaves and create a favorable nutritional environment are thus expected to have crucial fitness consequences. This is particularly true for leaf-mining herbivorous insects that strictly rely on deciduous leaf resources for growth, development, and reproduction (Giron et al. 2007; Kaiser et al. 2010). While senescent autumnal leaves represent a poor and declining source of nutrients, the 'green-islands' induced by leaf-miners enable the insect to fulfill its nutritional requirement and to survive under adverse conditions (unpublished results). It also allows the insect to win a race against time and hence the completion of a supplementary generation (Engelbrecht et al. 1969; Giron et al. 2007; Kaiser et al. 2010).

For the phytophagous leaf-mining moth Phyllonorycter blancardella, these 'green-islands' are characterized by an increased concentration in CKs leading to a favorable enriched nutritional environment due to an accurate CKmediated control of the overall sugar content (Giron et al. 2007; Kaiser et al. 2010; unpublished results). The moth relies on bacterial endosymbionts, most likely Wolbachia, to control the physiology of its host plant through manipulation of CK levels, thus increasing its fitness. Curing leafminers of their symbiotic partner results in the absence of 'green-island' formation on leaves, has been shown to increase compensatory larval feeding, and result in higher insect mortality (Kaiser et al. 2010). The origin of the CKs, the dynamics of the CK signal, and the potential nutritional consequences for leaf-miners, however, remain poorly understood. For instance, it is still unknown $(i)$ whether CKs are enhanced only in greenislands on yellow leaves; (ii) whether CKs are produced by the insect, the insect-symbiont combination, or the plant; or (iii) what the link is between CKs levels and plant sugar profiles.
In this study, we carried out a detailed biochemical investigation of plant CK and sugar profiles in the host-plant Malus domestica following attack by the leaf-miner caterpillar Phyllonorycter blancardella. First, to determine the extent of the CK-mediated phenotype ('green-island'), we identified and quantified the main CK families in leaf tissues both on green and yellow leaves. Second, as increased CK levels in infected leaf tissues can induce sugar accumulation (Elzen 1983; Engelbrecht et al. 1969; Frugier et al. 2008; Giron et al. 2007; Kaiser et al. 2010), we also determined the resulting sugar profiles in mined tissues. Beyond the commonly measured overall plant sugar content, we also characterized the specific sugar composition in leaf tissues to better understand the nature and consequences of the CKmediated phenotype. Finally, to investigate the role of bacterial symbionts on CK profiles, CK content was characterized in symbiont-free larvae and in larvae carrying the endosymbiotic bacteria Wolbachia.

\section{Methods and Materials}

Phyllonorycter blancardella (Fabricius 1781) (Lepidoptera: Gracillariidae) is a polyvoltine leaf-mining microlepidopteran of apple-trees. The first three instars (L1-L2-L3) are fluid-feeders (commonly referred to in the literature as 'sapfeeders') that set the outline of the mine and, therefore, the total surface available to later stages. The two following instars (L4-L5) are tissue-feeders and consume most of the mesophyll resulting in the formation of "feeding windows", translucent patches, where all tissues but the epidermis have been consumed. Both green and yellow mined (only one mine per leaf at the L4-L5 tissue-feeding larval stage) and unmined (neighboring leaf) leaves were collected in the field between 08:00 a.m. and 08:00 a.m. in autumn (November) on Malus domestica apple-trees, in a biologically managed orchard in Thilouze, France $\left(47^{\circ} 14^{\prime} 35^{\prime \prime}\right.$ North, $0^{\circ} 34^{\prime} 43^{\prime \prime}$ East). In order to study the CK and sugar concentrations of mined tissues, mined areas were dissected on ice following the exact outline of the mine, and were stored at $-80^{\circ} \mathrm{C}$ until analysis. Leaf-miner insects and frass were removed from the mine. Unmined green and yellow leaves were used as a control following the same procedure. Extracted larvae were individually identified, weighed, starved for $48 \mathrm{~h}$, and placed at $-80{ }^{\circ} \mathrm{C}$ for further $\mathrm{CK}$ analyses. To investigate the role of bacterial symbionts on $\mathrm{CK}$ profiles, larvae originating from antibiotic-fed females (symbiont-free larvae) were used in green-house experiments. Resulting L4 larvae and their corresponding leaf tissues were analyzed for CK profiles. Each leaf sample was ground in liquid nitrogen after lyophilization (Bioblock Scientific Alpha 1-4 LD plus lyophilizator) in order to have an extra-fine leaf powder. Five mg of mined and unmined control plant tissues were 
used to allow qualitative and quantitative comparisons (Sartorius micro-balance model 1801-001, Sartorius SA, Palaiseau, France).

Cytokinin Concentration of Mined Tissues According to Leaf Senescence Status Similar amounts of control and mined tissues $(5 \mathrm{mg})$ were extracted overnight in $80 \%$ aqueous methanol containing butylated-hydroxytoluene as antioxidant. Purification was performed by using a nitrocellulose prefilter ( $4.5 \mu \mathrm{m}$, Sartorius, Germany) connected to an Oasis cartridge (Hydrophilic-lipophilic-balanced reversed-phase extraction cartridge, Waters, USA) with a Teflon filter $(0.2 \mu \mathrm{m}$, Sartorius, Germany) at the outlet. CKs were eluted directly with $5 \mathrm{ml}$ of extraction solvent (Jourdain et al. 1997). Eluates were reduced by rotary evaporation, taken up with acidified water, and injected into a reverse-phase HPLC column (pump model Waters 600 Controller, colonne NovaPak C18 Waters $3.9 \times 150 \mathrm{~mm}$, Waters 996 photodiode array detector, Waters, USA). After sample injection $(100 \mu \mathrm{l})$, the column was eluted at $1 \mathrm{ml} \cdot \mathrm{min}^{-1}$ with a convex gradient of acidified water and pure acetonitrile (HPLC grade) until the eluant was $100 \%$ acetonitrile. Retention time of CKs was determined by separate and pooled injections of pure zeatin $(Z)$, ribosyl zeatin $(Z R)$, isopentenyladenine $(i P)$, and isopentenyl adenosine $(i P A)$ (Sigma, USA) as standards. Fractions centered on the retention time of each CK were collected (fraction collector Microcol TDC 80, Gilson, USA) and evaporated to dryness in a speed-vac concentrator (Savant, USA). CKs were measured using enzyme-linked immunosorbent assay (ELISA). ELISA quantification could be done because of a strict separation of each compound by HPLC fractionation (Jourdain et al. 1997). Isopentenyladenine $(i P)$ and isopentenyl adenosine $(i P A)$ were measured using anti-iPA polyclonal antibodies. Zeatin riboside $(Z R)$ and Zeatin $(Z)$ were measured using anti- $Z R$ polyclonal antibodies. ELISA was performed with microtitration plates (Nunc, Germany) coated with the antiserum appropriate to the assay being performed, and were incubated at room temperature in the dark overnight. Excess antiserum was removed by washing each plate $\times 4$ (distilled water with $0.1 \%$ photoflo), and a limited amount of hormone standard (iPA or $Z R$ ) or sample and anti-hormone antibody were then added. Blank controls and duplicates of CK standards in a logarithmic concentration series from 0 to $30 \mathrm{pM}$ were performed on each plate. Remaining wells were used for duplicated samples of HPLC fractions. Plates were incubated $2 \mathrm{~h}$ at $4{ }^{\circ} \mathrm{C}$ in darkness. After washing, anti-hormone antibodies bound to the plate were quantified. Optical densities were measured at $405 \mathrm{~nm}$, and values obtained from ELISAs were corrected for extraction and purification losses according to the percentage recovery of the tritiated adenine included in the sample extraction procedure. The antisera used are specific for the two families of isoprenoid CKs (isopentenyladenine- and zeatin-types) (Jourdain et al. 1997). These immunoreagents in combined HPLC-ELISA allow the identification and measurement of individual members of the $\mathrm{CK}$ families naturally occurring in plants at minute concentrations (lower limit of detection $=3$ fmol - Sotta et al. 1987). The advantage over standard GC-MS methods is that much smaller amounts of tissue are needed (see for example, Jourdain et al. 1997). Cross-reactivity between the two families was remarkably low, i.e., no more than $3 \%$ but typically less than $1.5 \%$, indicating that the individual antibodies were highly selective (Jourdain et al. 1997). The amounts of CKs obtained were expressed as fmole. $\mathrm{mg}^{-1}$ of plant material (dry weight). The exact amount of CKs in leaf tissues attributed to the presence of the leaf-miner (referred to as "extra-amount" of CKs in the text) was considered to be the total amount of CKs measured subtracted by the amount in the corresponding control (unmined green leaf or yellow leaf).

Sugar Quantification in Mined and Unmined Tissues According to Leaf Senescence Chlorophyll and other pigments were removed from similar amounts of control and mined tissues $(5 \mathrm{mg})$ with acetone $(100 \%)$ until complete elimination of natural coloration. Sugars then were extracted in $1 \mathrm{ml}$ aqueous methanol (80\%). After vortex and centrifugation at $1500 \mathrm{rpm}$, soluble sugars remain dissolved in the supernatant and were used for total soluble sugar quantification by colorimetric assays following established protocols (Giron et al. 2007), and individual sugars were assayed by capillary electrophoresis (Proteome lab ${ }^{\mathrm{TM}}$ PA800, 32Karat data acquisition software, Beckman Coulter) using a modification of Rovio's protocol optimizing sugars separation and data reproducibility (Rovio et al. 2007). Methanol extraction solutions were filtered with a $0.45 \mu \mathrm{m}$ filter (Millex, $4 \mathrm{~mm}$ diam, PVDF membrane, non sterile). Five hundred $\mu \mathrm{l}$ of each sample then were lyophilized before the addition of $18 \mu \mathrm{l}$ of MilliQ water and of $2 \mu \mathrm{l}$ of melezitose $50 \mathrm{mM}$, as an internal standard. The UV detection wavelength was $264 \mathrm{~nm}$ on a detection stripe of $6 \mathrm{~mm}$. For sample separation, we used a raw silica capillary of $50 \mu \mathrm{m}$ internal diam and $67 \mathrm{~cm}$ total length. The detection window was located at $57 \mathrm{~cm}$ from the injection end of the capillary. Samples and the capillary were maintained at $15{ }^{\circ} \mathrm{C}$. Samples were injected with a 0.5 psi pressure during $4 \mathrm{~s}$ corresponding to an injection volume of $2.77 \mathrm{nl}$ (http://www.beckmancoulter. com). The electrolyte was composed of $\mathrm{NaOH} 130 \mathrm{mM}$ and $\mathrm{Na}_{2} \mathrm{HPO}_{4} \cdot 12 \mathrm{H}_{2} \mathrm{O} 36 \mathrm{mM}, \mathrm{pH} 12.6$ (Rovio et al. 2007). The separation occurred at $16 \mathrm{kV}$ with a voltage linearly increasing from 0 to $16 \mathrm{kV}$ in $2 \mathrm{~min}$. The electrophoretic current was typically $90 \mu \mathrm{A}$. The maximal migration time was fixed at $60 \mathrm{~min}$. The control solution was composed of 7 standard sugars at $5 \mathrm{mM}$ (Sigma Aldrich, France): D-(+)-xylitol, D$(+)$-sorbitol, D-(+)-trehalose, D-(+)-melezitose (internal standard), D-(+)-saccharose, le D-(+)-glucose, and D-(+)-fructose. 
Between the two successive analyses, the capillary was rinsed with buffer for $2 \mathrm{~min}$ followed by MilliQ water for $12 \mathrm{~s}$. Data were processed with the $32 \mathrm{Karat}^{\mathrm{TM}}$ Software (version 7.0) allowing the determination of retention times and peak areas for each reference sugar (standards sugars - see above).

Quantification of Cytokinins in Larvae Following a $48 \mathrm{~h}$ starvation period in order to prevent any confounding effects of plant material (food) stored in the gut, quantification of CKs in starved L4-instars $\left(\mathrm{L}_{\mathrm{S}}\right)$ extracted from mined green and yellow leaves was performed using enzyme-linked immunosorbent assay as described previously. Results were expressed as fmole.larva ${ }^{-1}$. To confirm the absence of plant-derived CKs in samples, a second set of larvae was extracted from green and senescing leaves and directly dissected to remove their guts. CKs in dissected larvae $\left(\mathrm{L}_{\mathrm{D}}\right)$ were quantified as above. Finally, to control for the role of bacterial symbionts on larval CK profiles, larvae originating from antibiotic-fed females were allowed to develop on green and senescing leaves. Emerging females were kept with males for $3 \mathrm{~d}$ in Petri dishes containing $1 \%$ tetracycline and $40 \%$ glucose solution (see Kaiser et al. 2010 for details). Females then were individually placed on small 3-yr-old apple seedlings grown in a greenhouse for oviposition. Only females that had truly fed on the antibiotic solution and for which no bacterial endosymbionts were detected were used in the experiment. Preliminary experiments have proven that antibiotics have no toxic effects in this system and that results obtained are not due to side-effects of anti-biotics (Kaiser et al. 2010). Bacteria-free larvae (i.e., larvae treated by antibiotics: $\mathrm{L}_{\mathrm{T}}$ ) were either dissected to remove their guts $\left(\mathrm{L}_{\mathrm{TD}}\right)$ or starved for $48 \mathrm{~h}\left(\mathrm{~L}_{\mathrm{TS}}\right)$ and their cytokinin profiles were determined as above.

Statistical Analysis Statistical analyses were performed using R, v2.6.2 software. Data obtained were not normally distributed and, therefore, were analyzed by non-parametric tests. For CK content, data were analyzed by Wilcoxon tests or Kruskal-Wallis tests followed by Behrens-Fisher post-hoc tests. Comparisons between mined and unmined tissues for total soluble sugar content were processed using the KruskalWallis test and Behrens-Fisher post-hoc test when necessary. The sugar composition from different subsets of leaves/tissues was analyzed using multivariate analysis of variance (MANOVA). For MANOVA analyses, we used the Pillai's statistic test. Where significant effects were observed, posthoc comparisons were performed.

\section{Results}

Cytokinin Content Increases in Mined Tissues Independently of Leaf Senescence Status Phytohormone analysis revealed the presence of only three different types of CKs: isopentenyladenine $(i P)$, isopentenyl adenosine $(i P A)$, and zeatin $(Z)$ in mined and unmined apple-tree leaves (zeatin riboside $-Z R$ - was undetectable). According to the specificity of antisera used and the easy conversion between CKs and their conjugated forms (Jourdain et al. 1997; Mok and Mok 2001; Sakakibara 2006), data are presented for the two families of isoprenoid CKs: isopentenyladenine- and zeatintypes. The concentration of CKs naturally decreased with increasing leaf senescence status in intact leaves (green vs. yellow controls - Fig. 1A). The total CK content of mined tissues exceeded that of unmined green and yellow controls (Fig. 1A). Indeed, levels of $i P-i P A$ and $Z-Z R$ in mined tissues infested by L4 tissue-feeding larvae were significantly higher than control levels in both green and yellow leaves (Wilcoxon tests: $i P-i P A P<0.001, Z-Z R P<0.001, N=28-$ Fig. $1 \mathrm{~B}$ and $C)$. Green and yellow mined leaves showed a similar pattern, with $i P-i P A$ concentrations consistently higher than $Z-Z R$ concentrations. Despite greater global amounts of CKs in green leaves compared to yellow leaves (both in control and mined tissues), the extra-amount of CKs induced by the presence of the leaf-miner was similar in infested green and yellow leaves (Fig. 1B: extra-amount of $i P-i P A$ on green leaves $552 \pm 26$ fmole. $\mathrm{mg}^{-1}$, on yellow leaves $584 \pm 22$ fmole. $\mathrm{mg}^{-1}(N=14)$, Wilcoxon test: $P>0.05$, NS - Fig. 1C: extra-amount of $Z-Z R$ on green leaves $229 \pm 21$ fmole.mg ${ }^{-1}$, on yellow leaves $249 \pm 21$ fmole. $\mathrm{mg}^{-1}(N=14)$, Wilcoxon test: $P>0.05$, NS).

Leaf-Miners Maintain a Nutritional Homeostasis in Mined Tissues Individual sugar analysis revealed the presence of only five main sugars: sorbitol, trehalose, sucrose, glucose, and fructose. However, as trehalose was partially co-elued with another sugar and highly variable, data were not included in the present study in order to avoid large estimation errors for this sugar. Senescence leads to a metabolic reconfiguration of the leaves with a reduction of the total amount of sugars (green control: 104.0 $\pm 2.4 \mu \mathrm{g} . \mathrm{mg}^{-1}$, yellow control: $50.6 \pm 1.3 \mu \mathrm{g} . \mathrm{mg}^{-1}$; Behrens-Fisher test: $\left.P<0.001\right)$ and an alteration of the specific sugar composition (MANOVA: $F_{4,75}=18.49, P<0.001, N=25$; Fig. 2 - green controls vs. yellow controls). By contrast, mined tissues on green and yellow leaves show similar quantities of sugars (mined tissues on green leaves: $93.7 \pm 4.5 \mu \mathrm{g} . \mathrm{mg}^{-1}$, mined tissues on yellow leaves: $88.7 \pm 5.3 \mu \mathrm{g} . \mathrm{mg}^{-1}$; Behrens-Fisher test: $\quad P>0.05)$ and sugar composition (MANOVA: $F_{4,45}=0.99, P>0.05, N=75$; Fig. 2). Moreover, the total amount of sugars (Behrens-Fisher test: mine on green leaves vs. green control, $P>0.05$; mine on yellow leaves vs. green control, $P>0.05$ ) and the nutritional composition (MANOVA for sugar composition: mine on green leaves vs. green control, $F_{4,60}=0.82, P>0.05$; mine on yellow leaves vs. green control, $\left.F_{4,60}=0.61, P>0.05\right)$ of mined tissues is identical to unmined green leaves. The total soluble sugar content and 
Fig. 1 Cytokinin concentration of mined tissues according to leaf senescence status. A Effects of leaf-mining on levels of cytokinins in apple-tree leaves. B Isopentenyl $i P$ and

Isopentenyladenosine $i P A$, and C Zeatin $Z$ and ribosyl Zeatin $Z R$ concentrations in mined tissues infested by L4 tissuefeeding larvae compared to unmined control. Extraamounts of cytokinins induced by the presence of the leafminer were found to be similar on green and yellow leaves (Wilcoxon test: $P>0.05$, NS: not significant). Data are expressed as means \pm S.E. Nonmined green or yellow appletree leaves were used as a control. Statistical differences between means are shown by different letters $(a, b, c, d)$. $i P$ is shown with dotted patterns, $i P A$ with stripped patterns and $Z$ in white

Fig. 2 Sugar levels and composition in mined and control tissues according to leaf senescence. Specific composition of sugars in mined and unmined apple-tree leaf tissues both on green and on yellow leaves. The size of pies represents the total amount of soluble sugars. Proportions of sorbitol are shown in dotted patterns, sucrose in black, glucose in grey and fructose in white
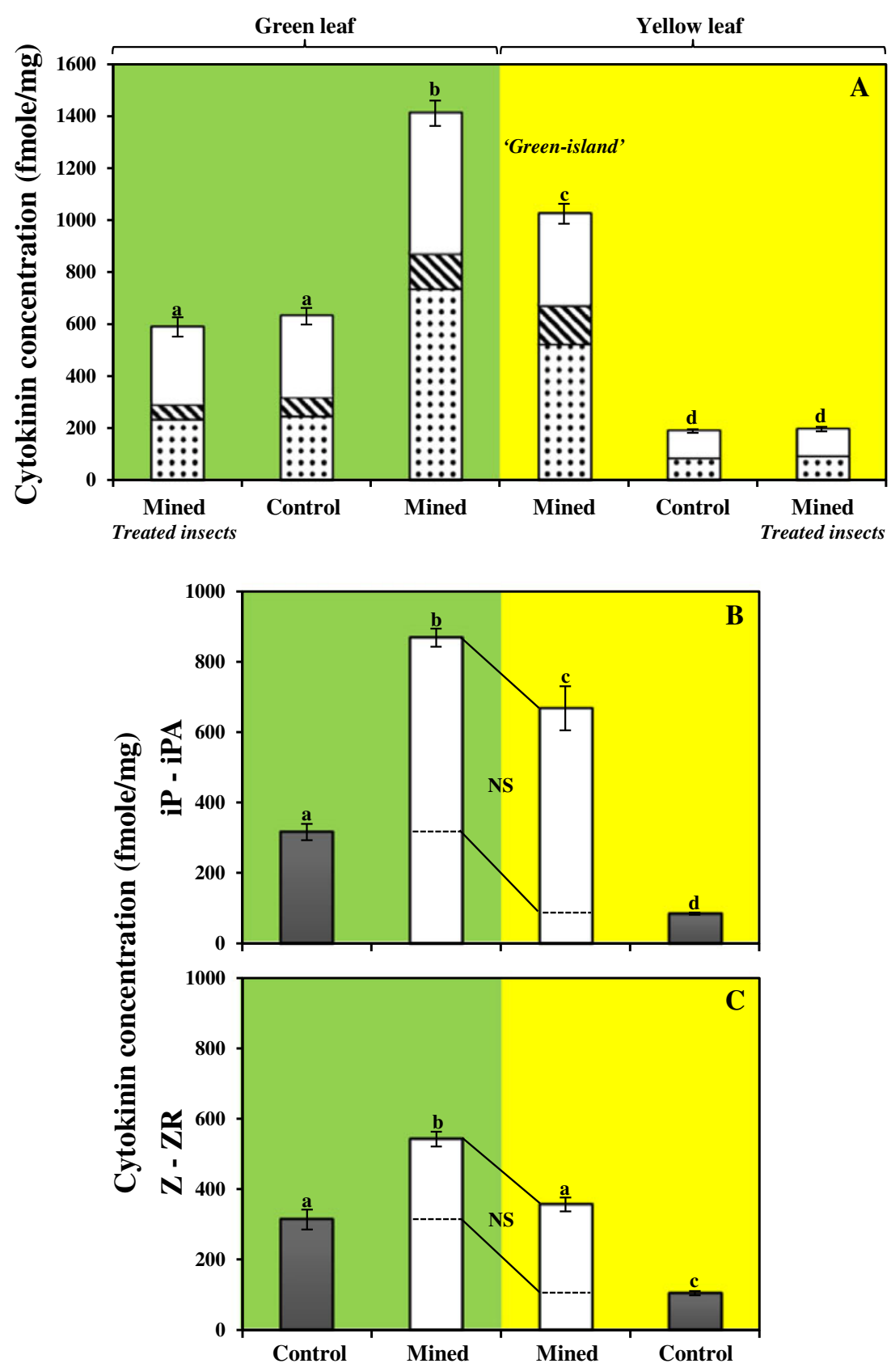
the specific sugar composition are, therefore, maintained constant in mined tissues compared to the green control, even during the senescence of the leaf.

Cytokinin Composition of Larvae Closely Matches Cytokinin Content of Infested Leaf Tissues The proportions of various types of CKs strongly differ in mined tissues compared to the unmined green and yellow controls (about $45-50 \%$ of $i P-i P A$ in controls and about 70-71\% in infested tissues; BehrensFisher test: $P<0.001-$ Fig. 3 ). Larvae (weight $=1.82 \pm 0.16$ $\mathrm{mg}$ ) exhibit significant amounts of CKs even when purged from any food remnants (Fig. 3 - Table 1). CK amounts and composition were similar for starved larvae $\left(\mathrm{L}_{\mathrm{S}}, N=16\right)$ and larvae where the gut was removed $\left(\mathrm{L}_{\mathrm{D}}, N=15\right)$ (Wilcoxon test: $P>0.05$, NS; Table 1). The relative proportion of CKs in larvae closely matches the relative proportion of $i P-i P A$ and $Z-Z R$ in extra-cytokinins (see Methods and Materials section for definition) induced by leaf-miners in mined tissues (Behrens-Fisher test: $P>0.05-$ Fig. 3). The level of $i P-i P A$ represents about $70 \%$ of measured CKs both in larvae and in extra-cytokinins measured in corresponding infested tissues. This result was found both in mined tissues on yellow and on green leaves.

Bacteria-Free Larvae Fail to Alter the Leaf Cytokinin Profile Larvae cured of their endosymbiotic bacteria do not show any detectable amounts of CKs (Table 1). Additionally, larvae free from endosymbiotic bacteria fail to modify the CK profile of mined leaf-tissues (Fig. 1A). Indeed, for larvae originating from antibiotic-fed females, mined tissues showed similar amounts of cytokinins to the control tissues both on green and yellow leaves (Kruskal-Wallis test: $P>0.05$ on green and yellow leaves; $N=25$ and 23, respectively).

\section{Discussion}

A markedly visible sign of leaf physiology alteration induced by the presence of a leaf-miner is undoubtedly the autumnal formation of 'green-islands' around mining caterpillars in senescing leaves. Previous studies have shown clearly a large accumulation of cytokinins (CKs) in mined tissues, which is responsible for the preservation of functional nutrient-rich green tissues at a time when leaves are otherwise turning yellow (Giron et al. 2007; Kaiser et al. 2010). However, this study shows that the plant physiology manipulation is not restricted to that senescent physiological state. Indeed, a similar pattern of $\mathrm{CK}$ accumulation occurs in mined tissues both on green and on yellow leaves. These results suggest a continuous production and/or accumulation of CKs in mined areas rather than an intermittent system taking place only in the fall, with the phenomenon tightly linked to the presence of the mining insect. 'Green-islands' appear as islands only because the leaf is turning yellow, and this might be the only visible part of an unexpected larger phenomenon. Whether or not plant physiology alteration is restricted to polyvoltine species and univoltine species with a long and late development extending into fall will need further investigation. Previous studies on Ectoedemia occultella, an univoltine leaf-miner species that develops on birch leaves from spring to fall, also showed the presence of 'green-island' (Engelbrecht 1971). Moreover, in that species, modification of the $\mathrm{CK}$ profile operates throughout the season. Indeed, alteration of the CK profile on birch leaves mined by E. occultella is observed at the first larval instar at a time when leaves are still green. Total amount of CKs in mined tissues then progressively increases with the mine's age to reach its maximum in September, right before the most intensive growth of the larva and shortly before leaves begin to turn yellow (Engelbrecht 1971; Engelbrecht et al. 1969). The seasonal visual appearance of green-islands illustrates how the study of plant-herbivore interactions could be impaired by focusing too much on the visible results of manipulations - galls are a striking example - rather than on the conditions, mechanisms, and fitness benefits (e.g., survival under adverse conditions vs. enhanced nutritional benefits) of the manipulation.

The maintenance of functional green tissues on senescing leaves is of considerable value to the development of the larvae, as it allows the insect to maintain a favorable nutritional environment in an otherwise degenerating context. Senescence is characterized by a profound alteration of plant metabolism and presents classically a strong remobilization
Fig. 3 Relative composition of cytokinins in larvae and corresponding mined tissues. Specific composition of cytokinins in mined leaf tissues of apple-tree (expressed as fmole. $\mathrm{mg}^{-1}$ ) and mining larvae (expressed as fmole.larva ${ }^{-1}$ ). Proportions of $i P-i P A$ are shown in grey and $Z-Z R$ in white

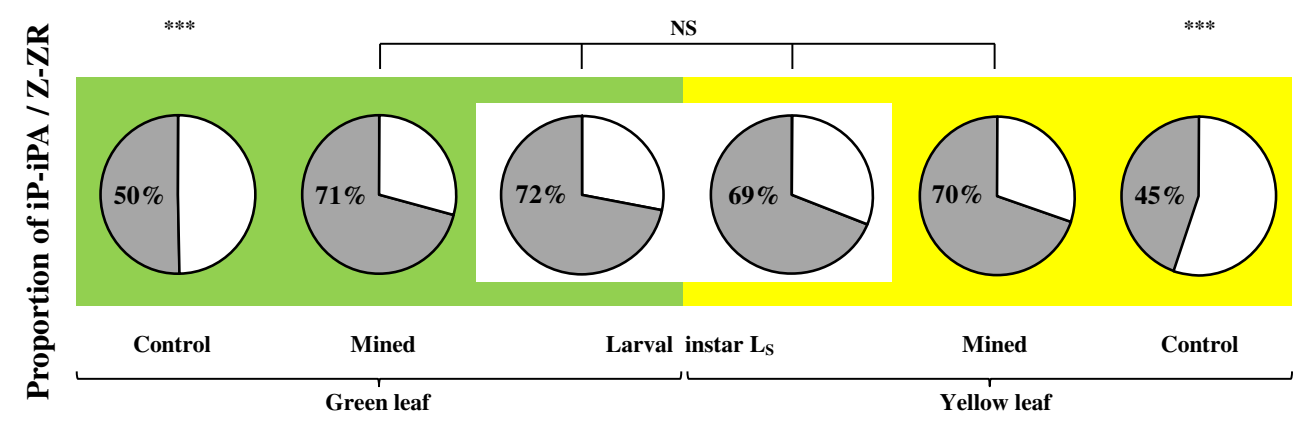


Table 1 Composition of cytokinins in larvae. Composition of cytokinins in starved $\left(\mathrm{L}_{\mathrm{S}}\right)$ and dissected $\left(\mathrm{L}_{\mathrm{D}}\right)$ larvae; and composition of cytokinins in starved $\left(\mathrm{L}_{\mathrm{TS}}\right)$ and dissected $\left(\mathrm{L}_{\mathrm{TD}}\right)$ antibiotic treated larvae
("Symbiont-free larvae"). Data are expressed as fmole.larva ${ }^{-1}$ and as means \pm S.E. Lower limit of detection LLD $=100 \mathrm{fM}$

\begin{tabular}{|c|c|c|c|c|}
\hline & \multicolumn{2}{|c|}{ Green leaves (fmole.larva ${ }^{-1}$ ) } & \multicolumn{2}{|c|}{ Yellow leaves (fmole.larva ${ }^{-1}$ ) } \\
\hline & iP - iPA & $\mathbf{Z}-\mathbf{Z R}$ & iP - iPA & Z-ZR \\
\hline \multirow{2}{*}{ Starved Larvae $\mathbf{L}_{\mathbf{S}}$} & $596 \pm 55$ & $231 \pm 13$ & $673 \pm 53$ & $295 \pm 19$ \\
\hline & $72 \%$ & $28 \%$ & $69 \%$ & $31 \%$ \\
\hline \multirow{2}{*}{ Dissected Larvae $\mathbf{L}_{\mathbf{D}}$} & $609 \pm 58$ & $248 \pm 14$ & $669 \pm 46$ & $259 \pm 24$ \\
\hline & $71 \%$ & $29 \%$ & $72 \%$ & $28 \%$ \\
\hline $\begin{array}{l}\text { Antibiotic-treated } \\
\text { Starved Larvae } \mathrm{L}_{\mathrm{TS}}\end{array}$ & \multicolumn{4}{|c|}{ Below detection level } \\
\hline $\begin{array}{l}\text { Antibiotic-treated } \\
\text { Dissected Larvae } \mathrm{L}_{\mathrm{TD}}\end{array}$ & \multicolumn{4}{|c|}{ Below detection level } \\
\hline
\end{tabular}

of sugars. Interestingly, despite the fact that plant chemical composition varies greatly in time and space, the induced alteration of the sugar profile (total quantity and specific composition) of mined tissues is similar on green and yellow leaves, suggesting an ability of the insect to maintain a nutritional homeostasis within the mine, even under two very distinct ecological conditions. Indeed, leaf-miner larvae appear to be able to regulate qualitatively and quantitatively the amount of sugars available at their feeding site thus matching nutritional intakes with energetic requirements (unpublished results) and buffering their feeding microenvironment from excessive variations, which can have profound effects on phytophagous insect preference and performance. As CKs are known to impact plant sugar metabolism, sugar composition of leaf tissues was the focus of the current study. However, nitrogen also is known to constrain insect herbivores growth and performances (Behmer 2009). Impact of leaf-mining on plant amino acids and proteins and their consequences will thus require further investigations.

Several studies have demonstrated that CKs are key factors that delay plant senescence and mediate plant sugar metabolism and transport (e.g., Lara et al. 2004; Mok and Mok 2001; Sakakibara 2006). Manipulating CKs levels would, thus, allow leaf-miners to prevent mined tissues from senescing and to keep their nutritional composition similar to unmined green leaves on both green and yellow leaves. However, the sugar profiles in mined tissues on green and yellow leaves are similar despite different amount of CKs. This confirms that not only are $\mathrm{CK}$ quantities in various plant tissues important but, also important are ( $i$ ) the type of CKs, which may differ if they are originating from the plant or from the biotic invaders; (ii) the nature of the target cells/tissues; (iii) the developmental state of the plant; and (iv) the hormonal balance between CKs and other phytohormones such as auxin (Farnsworth 2004; Frebort et al. 2011; Giron et al. 2013; Hare et al. 1997). How the CK signal evolves over the course of the insect development (regarding successive larval stages with different requirements and/or feeding habit for example) and how this impacts the plant primary and secondary metabolism also remains to be investigated (Giron et al. 2013).

Changes in plant nutritional quality according to ontogenetic processes (maturation), physiological processes (senescence), abiotic or biotic environmental variables have been shown to strongly affect the population dynamics of a broad range of phytophagous insects (e.g., Feeny 1970; Raupp and Denno 1983). Decrease in foliar nutritional quality with leaf age due to maturation and senescing processes constrains many phytophagous insects to a single generation in a season (e.g., Feeny 1970; Potter and Kimmerer 1989). Additionally, positive effects of carbohydrate, protein and/or amino acid leaf content on offspring (survival, development time, size) and on adults (realized fecundity) performances as well as behaviors (feeding and oviposition preferences) frequently are observed (Egan and Ott 2007; Scheirs et al. 2001; Stiling et al. 1999). Variations in foliar nutritional quality ranging from 1.1 to 1.5 fold have been found to be sufficient to significantly affect important offspring performance factors, such as survival and pupal size in the leafminer Chromatomyia milii on creeping velvet grass (Scheirs et al. 2001). In our system, besides buffering seasonal consequences of senescence, maintenance of the nutritional quality of leaf tissues consumed is expected to affect the feeding behavior (e.g., time spent feeding or amount of plant tissues consumed) and life-history traits of larvae (e.g., developmental time). Both factors likely minimize predation risk by shortening the predator-sensitive phase (larval and pupal instars) and by reducing the number of feeding windows (areas where all but the upper epidermis has been consumed by the caterpillar) thus limiting parasitoid attacks and excessive radiations (Djemaï et al. 2000; Pincebourde and Casas 2006; Pincebourde et al. 2006). 
The finding of CKs inside larvae emptied of plant remains - in proportions similar to mined tissues - suggests that some (if not all) extra-cytokinins in mined tissues originate from the insect. The similarity of CK profiles in starved and dissected larvae concomitant with the absence of detectable amounts of CKs in antibiotic treated larvae strongly suggest that (i) CKs detected in larvae are not plant-derived CKs that would have been stored, and that (ii) release of CKs in the plant is an insect-endosymbiotic bacteria-mediated mechanism. The possibility that CKs found in larvae are plant-derived CKs that would have been sequestered thanks to endosymbiotic bacteria is a complicated hypothesis. A clear rejection would require feeding larvae on CK-free tissues - which unfortunately is impossible due to the key regulatory role of CKs in plant growth and development - or rearing them on artificial diet - a step that has not been successful for any leaf-miner Lepidopteran species so far. The second hypothesis is supported by the absence of altered CKs profiles in the mine when larvae are cured from their endosymbionts (and then do not contain CKs themselves). The ability to produce CKs has been demonstrated clearly in different plant-associated organisms including bacteria, fungi, nematodes, and herbivorous insects (Frugier et al. 2008; Giron et al. 2013; Walters et al. 2008). A conclusive demonstration of the exact origin of CKs in our system would require complex genome-wide sequencing and/or labelling approaches.

Plants and their biotic fellows, from microbes to insects, share numerous signaling systems and pathways, and new examples constantly arise (Giron et al. 2013; Pieterse and Dicke 2007; Schultz 2002; Schultz and Appel 2004; Walters and McRoberts 2006). These signals control functions ranging from morphogenesis to senescence, from immunity to reproduction, and provide recognition of kin from non-kin. Sharing somewhat similar signals give plants and herbivores the unique opportunity to recognize signals emitted by each other and to use them for their own benefit. This could, for example, allow plants to initiate appropriate defense responses or allow herbivores to manipulate/regulate the related signaling systems of the plant (e.g. Giron et al. 2013; Hatcher et al. 2004; Kessler and Baldwin 2002; Mopper et al. 2004). Endophagous insects may share metabolic pathways with plants that may allow them to perceive, interpret, and/or manipulate plant signals for their own purposes. Such similar hormonal systems, whether homologous or convergent, have undoubtedly an adaptive value as well as strong ecological and evolutionary consequences, as they allow insects to cope with multiple selective pressures by generating optimal microenvironments.

Acknowledgements This work was supported by the ANR grant $\mathrm{n}^{\circ}$ ANR-05-JCJC-0203-01 and the Région Centre grant ENDOFEED 201000047141 to David Giron. Further support was also provided by the National Centre of Scientific Research (CNRS) and the University François-Rabelais. We thank Laurent Ardouin for full access to his orchard and Jean-Philippe Christidès, Arnaud Lanoue, Gaëlle Glevarec, Elisabeth Huguet, Benoît St-Pierre and Nadine Imbault for their help with the laboratory work and helpful discussions. We also thank 3 anonymous referees and the editor for helpful comments on the manuscript.

\section{References}

Behmer ST (2009) Insect herbivore nutrient regulation. Annu Rev Entomol 54:165-187

Djemaï I, Meyhöfer R, Casas J (2000) Geometrical games between a host and a parasitoid. Am Nat 156:257-265

Egan SP, Ott JR (2007) Host-plant quality and local adaptation determine the distribution of a gall-forming herbivore. Ecology 88:2868-2879

Ehneß R, Roitsch T (1997) Co-ordinated induction of mRNAs for extracellular invertase and a glucose transporter in C. rubrum by cytokinins. Plant J 11:539-548

Elzen GW (1983) Cytokinins and insect galls. Comp Biochem Physiol 76:17-19

Engelbrecht LU (1971) Cytokinin activity in larval infected leaves. Biochem Physiol Pflanzen 162:9-27

Engelbrecht L, Orban U, Heese W (1969) Leaf-miner caterpillars and cytokinins in the "green islands" of autumn leaves. Nature 223:319-321

Erb M, Meldau S, Howe GA (2012) Role of phytohormones in insectspecific plant reactions. Trends Plant Sci 17:250-259

Farnsworth E (2004) Hormones and shifting ecology throughout plant development. Ecology 85:5-15

Feeny P (1970) Seasonal changes in oak leaf tannins and nutrients as a cause of spring feeding by wintermoth caterpillars. Ecology 51:565-581

Frebort I, Kowalska M, Hluska T, Frebortova J, Galuszka P (2011) Evolution of cytokinin biosynthesis and degradation. J Exp Bot 62:2431-2452

Frugier F, Kosuta S, Murray JD, Crespi M, Szczyglowski K (2008) Cytokinin: secret agent of symbiosis. Trends Plant Sci 13:115120

Giron D, Frago E, Glevarec G, Pieterse CMJ, Dicke M (2013) Cytokinins as key regulators in plant-microbe-insect interactions: connecting plant growth and defence. Funct Ecol 27:599-609

Giron D, Kaiser W, Imbault N, Casas J (2007) Cytokinin-mediated leaf manipulation by a leafminer caterpillar. Biol Lett 3:340-343

Godt DE, Roitsch T (1997) Regulation and tissue-specific distribution of mRNAs for three extracellular invertase isozymes of tomato suggests an important function in establishing and maintaining sink metabolism. Plant Physiol 115:273-282

Gottlieb D, Garner JM (1946) Rust and phosphorus distribution in wheat leaves. Phytopathology 36:557-64

Hare PD, Cress WA, Van Staden J (1997) The involvement of cytokinins in plant responses to environmental stress. Plant Growth Regul 23:79-103

Hatcher PE, Moore J, Taylor JE, Tinney GW, Paul ND (2004) Phytohormones and plant-herbivore-pathogen interactions: integrating the molecular with the ecological. Ecology 85:59-69

Jameson P (2000) Cytokinins and auxins in plant pathogen interactions an overview. Plant Growth Regul 32:369-380

Jourdain I, Lelu M-A, Label P (1997) Hormonal change during growth of somatic embryogenic masses in hybrid larch. Plant Physiol Biochem 35:741-749 
Kaiser W, Huguet E, Casas J, Commin C, Giron D (2010) Plant greenisland phenotype induced by leaf-miners is mediated by bacterial symbionts. Proc R Soc B 277:2311-2319

Kessler A, Baldwin IT (2002) Plant responses to insect herbivory: the emerging molecular analysis. Annu Rev Plant Biol 53:299-328

Lara MEB, Garcia MCG, Fatima T, Ehneß R, Lee TK, Proels R, Tanner W, Roitsch T (2004) Extracellular invertase is an essential component of cytokinin-mediated delay of senescence. Plant Cell 16:12761287

Meldau S, Erb M, Baldwin IT (2012) Defence on demand: mechanisms behind optimal defence patterns. Ann Bot 110:1503-1514

Mok DW, Mok MC (2001) Cytokinin metabolism and action. Annu Rev Plant Physiol Plant Mol Biol 52:89-118

Mopper S, Wang Y, Criner C, Hasenstein K (2004) Iris hexagona hormonal responses to salinity stress, leafminer herbivory, and phenology. Ecology 85:38-47

Mothes K, Engelbrecht L (1961) Kinetin-induced directed transport of substances in excised leaves in the dark. Phytochemistry 1:58-62

Mothes K (1964) The Role of Kinetin in Plant Regulation. Colloq Int CNRS 123:131-141

Pieterse CMJ, Dicke M (2007) Plant interactions with microbes and insects: from molecular mechanisms to ecology. Trends Plant Sci 12:564-569

Pincebourde S, Casas J (2006) Multitrophic biophysical budgets: thermal ecology of an intimate herbivore insect-plant interaction. Ecol Monogr 76:175-194

Pincebourde S, Frak E, Sinoquet H, Regnard J-L, Casas J (2006) Herbivory mitigation through increased water-use efficiency in a leaf-mining moth-apple tree relationship. Plant Cell Environ 29:2238-2247

Potter DA, Kimmerer TW (1989) Inhibition of herbivory on young holly leaves: evidence for the defensive role of saponins. Oecologia 78:322-329
Raupp MJ, Denno RF (1983) Leaf age as a predictor of herbivore distributions and abundance. In: Denno RF, McClure MS (eds) Variable plants and herbivores in natural and managed systems. Chapman and Hall, London, pp 91-124

Robert-Seilaniantz A, Navarro L, Bari R, Jones JDG (2007) Pathological hormone imbalances. Curr Opin Plant Biol 10:372-379

Rovio S, Yli-Kauhaluoma J, Sirén H (2007) Determination of neutral carbohydrates by CZE with direct UV detection. Electrophoresis 28:3129-3135

Sakakibara H (2006) Cytokinins: activity, biosynthesis, and translocation. Annu Rev Plant Biol 57:431-44

Scheirs J, de Bruyn L, Verhagen R (2001) Seasonal changes in leaf nutritional quality influence grass miner performance. Ecol Entomol 27:84-93

Schultz JC (2002) Shared signals and the potential for phylogenetic espionage between plants and animal. Integr Comp Biol 42:454-462

Schultz JC, Appel HA (2004) Cross-kingdom cross-talk: Hormones shared by plants and their insect herbivores. Ecology 85:70-77

Shaw M, Samborski DJ (1956) The physiology of host-parasite relations. IX Can J Bot 39:1393-1407

Sotta B, Pilate G, Pelese F, Sabbagh I, Bonnet M, Maldiney R (1987) An avidin-biotin solid phase ELISA for femtomole Isopentenyladenine and Isopentenyladenosine measurements in HPLC purified plant extracts. Plant Physiol 84:571-573

Stiling P, Rossi AM, Hungate B, Dijkstra P, Hinkle CR, Knott WM III, Drake B (1999) Decreased leaf-miner abundance in elevated CO2: Reduced leaf quality and increased parasitoid attack. Ecology 9:240-244

Walters DR, McRoberts N (2006) Plants and biotrophs: A pivotal role for cytokinins? Trends Plant Sci 11:581-586

Walters DR, McRoberts N, Fitt BDL (2008) Are green islands red herrings? Significance of green islands in plant interactions with pathogens and pests. Biol Rev 83:79-102 